\title{
O Programa de Regionalização de Minas Gerais, Brasil: aspectos históricos, fragilidades e perspectivas
}

Isabela Rosa Settea

\section{Resumo}

Este artigo tem como objetivo realizar uma análise geral do Programa de Regionalização do Turismo em Minas Gerais, abordando os principais aspectos históricos da formação da Secretaria de Estado de Turismo de Minas Gerais (Setur-MG) e da política de regionalização e propondo uma reflexão acerca das principais fragilidades e perspectivas do projeto. Além da observação participante, a pesquisa envolveu uma análise bibliográfica e aplicação de entrevistas com representantes da Setur-MG, da Federação de Circuitos Turísticos (Fecitur), do CET-MG e gestores de circuitos turísticos de diversas regiões do estado. Percebeu-se que muitas fragilidades vivenciadas pelos circuitos turísticos já apontadas em estudos anteriores não foram superadas, com destaque para a dificuldade financeira agravada pela alta inadimplência dos municípios associados e acentuada pela crise econômica e financeira do país. Como perspectivas, constatou-se que há grande expectativa em relação à criação da Lei Geral do Turismo de MG, que pretende reconhecer a existência dos Circuitos Turísticos. A necessidade de revisão dos critérios de habilitação no ICMS Turístico e o aumento da alíquota destinada ao turismo também foram apontados como necessários. É fundamental que a Setur-MG, enquanto órgão gestor e indutor do programa, promova medidas em parceria com os circuitos turísticos e a Fecitur visando a melhoria da capacidade de gerenciamento dos circuitos, assim como um fortalecimento das entidades em seus territórios rumo ao efetivo empoderamento e protagonismo das regiões.

Palavras-chave: Turismo; Circuitos turísticos; Regionalização; Governança.

\section{Abstract \\ Regionalization program of Minas Gerais, Brazil: historical aspects, fragilities and perspectives}

This article aims at performing a general analysis of the Tourism Regionalization Program in Minas Gerais, approaching the main historical aspects of the formation of the State Secretariat of Tourism of Minas Gerais (Setur-MG in the Portuguese acronym) and the regionalization policy, as well as proposing a reflection regarding the main fragilities and perspectives of the project. Besides the participant observation, the research involved a bibliographic analysis and interviews conduction with representatives from Setur-MG, from the Federation of Tourist Circuits (Fecitur in the Portuguese acronym), from the State Council of Tourism of Minas Gerais (CET-MG in the Portuguese acronym) and tourist circuits managers from several areas of the state. It was noticed that many fragilities experienced by the tourist circuits already indicated in previous studies have not been overcome, with emphasis on the financial difficulty worsened by the associated municipalities' high delinquency rate and economic and financial crisis in the country.

a. Mestranda em Turismo pela Escola de Artes, Ciências e Humanidades da Universidade de São Paulo. Especialista em Gestão Pública pela Fundação João Pinheiro. Especialista em Turismo e Desenvolvimento Sustentável pela Universidade Federal de Minas Gerais. Bacharel em Turismo pela Pontifícia Universidade Católica de Minas Gerais. São Paulo, São Paulo, Brasil. E-mail: isabelasette@usp.br 
As perspectives, it was verified that there is great expectation regarding the creation of the General Law of Tourism of Minas Gerais, which aims at recognizing the existence of the Tourist Circuits. The necessity of revision of the criteria for qualification in the Tourism ICMS (Tourism Goods and Services Tax) and the increase in the tax collection portion for tourism have been also pointed out as necessary. It is essential that the Setur-MG, as the managing and encouraging body of the program, promotes measures in partnership with the tourist circuits and Fecitur, aiming at the improvement of the capacity of the circuits' management, as well as the strengthening of the institutions in their territories towards an effective empowerment and protagonism of the regions.

Keywords: Tourism; Tourist circuits; Regionalization; Governance.

\section{Resumen}

\section{El programa de regionalización de Minas Gerais, Brasil: aspectos históricos, debilidades y perspectivas}

El artículo tiene como objetivo realizar un análisis general del Programa de Regionalización del Turismo de Minas Gerais, enfocando los principales aspectos históricos de la formación de la Secretaria de Estado de Turismo de Minas Gerais (Setur-MG) y de la política de regionalización y, proponiendo una reflexión sobre las principales debilidades y perspectivas del proyecto. Además de la observación participante, la investigación consistió en un análisis de la literatura y en la aplicación de entrevistas con representantes de la Setur-MG, de la Federação de Circuitos Turísticos (Fecitur), del Conselho Estadual de Turismo (CET-MG) y gestores de circuitos de turismo de diferentes regiones del estado. Se observó que muchas debilidades ya senãladas en estudios anteriores acerca de los circuitos no fueron superadas, especialmente las dificultades financieras exacerbadas por el alto endeudamiento de los municipios asociados y acentuadas por la crisis económica y financiera en el país. Como perspectiva, se ha descubierto que hay una gran expectativa para la creación de la Ley General de Turismo de MG que, entre otras cosas, pretende reconocer la existencia de los Circuitos Turísticos. La revisión de los criterios de elegibilidad en el ICMS Turístico y el aumento de la tasa destinada al turismo también fueron señalados como necesarios. Es esencial que la Setur-MG, como cuerpo inductor del programa de gobierno, promueva medidas en asociación con los Circuitos Turísticos y Fecitur destinadas a mejorar las capacidades de gestión de los circuitos y a fortalecer las entidades en sus territorios hacia el empoderamiento y efectivo protagonismo de las regiones.

Palabras clave: Turismo; Circuitos turísticos; Regionalización; Gobernancia.

\section{INTRODUÇÃo}

0 turismo em Minas Gerais tem suas origens ligadas às estâncias hidrotermais, valorizadas pelo valor terapêutico das suas águas principalmente nos séculos XIX e XX, com destaque para os hotéis-cassinos luxuosos na região do sul do estado (PEREIRA, 1999).

Apesar de ocorrerem iniciativas ligadas a políticas públicas de turismo desde a década de 1940, apenas na década de 1990 é criada uma Secretaria de Estado com atribuição exclusiva de trabalhar o desenvolvimento turístico de Minas Gerais. E é a partir da criação de uma secretaria que se inicia o processo de regionalização do turismo no estado, sendo o fato mais marcante dessa trajetória o início dos Circuitos Turísticos (PEREIRA, 1999).

Os Circuitos Turísticos integram a política de regionalização do turismo no estado de Minas Gerais e são reconhecidos por meio de decreto estadual desde 
2003 (MINAS GERAIS, 2003a). Tais circuitos surgiram a partir da diretriz de descentralização e adoção de medidas participativas voltadas ao desenvolvimento regional, pautadas nos princípios da integração e cooperação entre os municípios (TRINDADE, 2009).

Nesse sentido, a formação dos Circuitos Turísticos buscou estimular um processo endógeno de desenvolvimento turístico, a partir da organização e mobilização dos próprios municípios. Vale destacar que o conceito de desenvolvimento é complexo, tendo sido alvo frequente de discussão nas ciências sociais. 0 entendimento acerca do desenvolvimento turístico deve ir além da ótica puramente econômica das teorias de crescimento e modernização, abordando também outras dimensões. Nesse sentido, o conceito de desenvolvimento turístico sustentável surge com a preocupação de ampliar a lógica economicista para as questões ligadas às dimensões culturais, sociais, ambientais, entre outras (CORIOLANO; SAMPAIO, 2012; HALL, 2000).

Ao longo dos anos, a política de regionalização de Minas Gerais obteve significativos avanços e conquistas que seguem contribuindo com o desenvolvimento turístico no estado. Porém, os desafios para sua consolidação e o efetivo empoderamento e protagonismo das regiões no que diz respeito ao turismo ainda são muitos.

Diante desse contexto, este artigo tem como objetivo realizar uma análise geral do Programa de Regionalização do Turismo em Minas Gerais, abordando os principais aspectos históricos da formação da Secretaria de Estado de Turismo de Minas Gerais (Setur-MG) e da política de regionalização e propondo uma reflexão acerca das principais fragilidades e perspectivas do projeto. Para subsidiar essa reflexão, foram feitas entrevistas com gestores da Setur, membros do Conselho Estadual de Turismo (CET-MG) e da Federação de Circuitos Turísticos (Fecitur), além de gestores de circuitos de diversas regiões do estado.

\section{MÉTODOS}

Este artigo se baseia em uma pesquisa de natureza qualitativa, descritiva e exploratória.

De acordo com Veal (2011), a pesquisa descritiva tem a função de investigar e apresentar/descrever o objeto de estudo, sem ter o objetivo de explicá-lo propriamente. A abordagem qualitativa busca a compreensão do comportamento de determinado tema e não apresenta, normalmente, dados numéricos. Segundo o autor, um dos "pressupostos básicos da pesquisa qualitativa é que a realidade não é construída de forma objetiva, mas social e subjetivamente" (VEAL, 2011, p. 264).

O procedimento de campo envolveu pesquisa documental e bibliográfica, além da aplicação de entrevistas com questões abertas. A pesquisa bibliográfica considerou artigos e publicações em periódicos, dissertações, teses e relatórios de pesquisa. Foram pesquisados também leis, normas, decretos, resoluções e documentos oficiais da Setur-MG e do Ministério do Turismo. Buscou-se traçar a trajetória da política estadual de turismo de Minas Gerais, bem como a formação dos Circuitos Turísticos, além da correlação entre o objeto e abordagens ligadas a governança. 
As entrevistas foram realizadas durante os meses de maio e junho de 2016 com o intuito de identificar as fragilidades e perspectivas ligadas ao Programa de Regionalização do Turismo de Minas Gerais. Tais entrevistas foram feitas com representantes da Setur-MG (secretário-adjunto de turismo, superintendente e diretores da Superintendência de Políticas do Turismo), representantes da Fecitur e do Conselho Estadual de Turismo de Minas Gerais e gestores de circuitos turísticos da maior parte das regiões administrativas do estado. Foram encaminhados 25 questionários e obtidas quinze respostas, sendo quatro de gestores da Setur-MG, uma da Fecitur, uma do CET-MG e dez de gestores de circuitos turísticos.

As perguntas norteadoras das entrevistas foram relacionadas a: (1) dificuldades e fragilidades ainda encontradas pelo Programa de Regionalização e os Circuitos Turísticos; (2) perspectivas de mudança nesse cenário para os próximos dez anos; (3) opinião dos entrevistados sobre a crise econômica e política pela qual o Brasil vem passando e sua influência nos rumos da política nacional e estadual de turismo; (4) perspectiva de institucionalização dos circuitos por Lei Estadual; e (5) desafios e cenários futuros para o Programa de Regionalização de Minas Gerais.

Em função da autora deste artigo ter trabalhado na área de políticas de turismo da Setur-MG de 2008 a 2012, utilizou-se também, ainda que em menor grau, a técnica de observação participante, quando o pesquisador "torna-se parte do processo social que está sendo estudado" (VEAL, 2011, p. 275).

\section{ASPECTOS HISTÓRICOS DA FORMAÇÃO INSTITUCIONAL DA POLÍTICA DE TURISMO DE MINAS GERAIS}

Conforme destacado, na segunda metade do século XIX, o estado de Minas Gerais começou a atrair os primeiros visitantes para os municípios de tradição termal/hidromineral. No entanto, é a partir do século XX que essa tendência se confirma, impulsionando a construção de hotéis e estâncias glamorosas, nos moldes das que então existiam na Europa (BARBOSA, 2012). Bolson (2006, p. 75) reitera que, no final do século XIX e início do século XX, o Governo Federal investiu em melhorias nessas localidades, sendo essa uma das "primeiras ações do Estado em prol da atividade turística de Minas Gerais".

Para melhor contextualização da política de turismo em Minas Gerais, é importante explicitar também o contexto nacional do setor. Segundo Araújo e Taschner (2012), a primeira fase da política pública de turismo no Brasil vai da década de 1930 até a edição do Decreto-Lei no 55 de 1966. Tal período é marcado pela criação, em 1939, do primeiro organismo oficial de turismo (a Divisão de Turismo, como parte do Departamento de Imprensa e Propaganda, vinculado à Presidência da República), pela criação do primeiro diploma legal que trata exclusivamente do turismo no contexto nacional (Decreto-Lei no 2.440/1940) e pela proibição dos jogos de azar em 1946. 0 fato mais relevante do período é, no entanto, a edição do Decreto-Lei no 55/1966, que define pela primeira vez uma política nacional para o setor e cria o Conselho Nacional de Turismo (CNTur) e a Empresa Brasileira de Turismo (Embratur) (ARAÚJO; TASCHNER, 2012). 
Ainda segundo Araújo e Taschner (2012), a segunda fase de política pública nacional de turismo se dá a partir da criação do Decreto-Lei no 55/1966 e vai até a reestruturação da Embratur pela Lei no 8181/1991. Nesse período, o turismo começa a ser entendido como possível ferramenta para diminuir as diferenças regionais e contribuir com a dinamização econômica dos territórios.

Já a terceira fase da política de turismo brasileira se inicia em 1991 e segue até os dias atuais. Esse período é marcado pela reestruturação da Embratur (por meio da Lei no 8181/1991), que se torna uma autarquia e incorpora a atribuição de formular, coordenar e executar a política nacional de turismo; pelo lançamento, em 1992, do Plano Nacional de Turismo (Plantur), cujos programas não chegaram a ser efetivamente implantados, e pelas criações do Programa Nacional de Municipalização do Turismo (PNMT) em 1994, do Ministério do Turismo em 2003 e do Programa de Regionalização do Turismo (PRT) em 2004 (ARAÚJO; TASCHNER, 2012). Tais programas (PNMT e PRT) foram bases importantes da política nacional no setor. Segundo Trentin e Fratucci (2011, p. 841), o PNMT envolvia uma "inversão nos processos decisórios da gestão do turismo brasileiro", passando da esfera federal para a lógica local. Já o PRT enfocava as regiões turísticas em vez dos municípios, tendo como um dos objetivos o fortalecimento da gestão turística regional, tendo sido influenciado pela política de Minas Gerais (BRASIL, 2010).

Voltando ao estado de Minas Gerais, a primeira menção legal ao turismo se dá na década de 1940, a partir do Departamento Estadual de Imprensa e Propaganda (seguindo, portanto, a lógica nacional), onde a propaganda, a publicidade e o turismo ficavam sob a alçada da Divisão de Divulgação (BOLSON, 2006).

Em 1960, cria-se a Hidrominas - Águas Minerais de Minas Gerais S/A por meio da Lei Estadual no 2.268. Tratava-se de uma sociedade de economia mista destinada ao aproveitamento e industrialização dos recursos minerais e ao desenvolvimento do turismo (MINAS GERAIS, 1960) que teve incorporado ao seu capital social alguns importantes hotéis, equipamentos e balneários mineiros, tais como o Grande Hotel de Araxá, o Parque das Águas de Caxambu e o Palace Hotel de Poços de Caldas, entre outros (GOMES, 2006).

Na década de 1970 (portanto, após a definição de uma política nacional de turismo pela primeira vez em âmbito nacional), o turismo foi contemplado no Primeiro e no Segundo Plano Mineiro de Desenvolvimento Econômico e Social (PMDES), elaborados em 1971 e em 1975, respectivamente. No entanto, tais documentos pouco contribuíram com o desenvolvimento do turismo no estado, uma vez que não havia um órgão executivo com a função de estimular o desenvolvimento do setor, tampouco recursos financeiros disponíveis para investimento. (PEREIRA, 1999)

No final da década de 1970, é criada a Agência de Desenvolvimento Turístico de Minas Gerais (Adetur-MG) com o intuito de implementar o primeiro Programa Mineiro de Turismo (Promitur). No entanto, segundo Trindade (2009), a agência não conseguiu atingir os objetivos propostos na sua criação por, dentre outros motivos, não ter agilidade administrativa e financeira.

A Empresa Mineira de Turismo - Turminas foi criada em 1979 por meio da Lei Estadual no 7.658 (MINAS GERAIS, 1979), substituindo a Adetur, extinta na ocasião. A Turminas era uma empresa pública de direito privado, que tinha, en- 
tre suas competências, a "operacionalização de programas e projetos de apoio e incentivo ao turismo" (MINAS GERAIS, 1979, art. 2º).

Na década de 1980, a cidade de Ouro Preto recebeu o título de Patrimônio Cultural da Humanidade pela Unesco, o que, segundo Gomes (2006), teria dado destaque à preservação e à restauração do patrimônio histórico de Minas Gerais.

No ano de 1983, são criados o Sistema Operacional de Esportes, Lazer e Turismo e a Secretaria de Estado de Lazer, Esporte e Turismo (Selt-MG), regulamentada pelo Decreto Estadual 23.373 de 1984, que estabelecia como colegiado integrante da Secretaria o Conselho Estadual de Turismo. A Turminas e Hidrominas passam então a ser entidades vinculadas à Selt-MG, assim como a Administração de Estádios do Estado de Minas Gerais (ADEMG) e a Companhia Mineira de Promoções (Prominas), criada em 1981 com a finalidade de atuar na captação e desenvolvimento do turismo de negócios. (MINAS GERAIS, 1984).

De acordo com Bolson (2006), no fim da década de 1980, a Turminas assume como responsabilidade o cadastramento, registro e fiscalização das empresas ligadas ao setor de turismo no estado, enquanto a Hidrominas inicia o processo de privatização do seu patrimônio.

Em 1989, o turismo é contemplado com uma seção exclusiva na Constituição Estadual de Minas Gerais (Capítulo II, Da Ordem Econômica), que estabeleceu como dever do Estado o apoio e incentivo ao turismo como atividade econômica, reconhecendo o valor do setor para o desenvolvimento social e cultural e dispondo sobre a criação de uma política estadual de turismo. Neste documento, percebe-se uma menção ao turismo regional, no que diz respeito a sua divulgação (MINAS GERAIS, 2017).

Apenas em 1994 é que se estabelece efetivamente um plano que define a política estadual de turismo: trata-se do Plano Integrado para o Desenvolvimento do Turismo em Minas Gerais (Planitur-MG), instituído pela Lei Estadual no 11.483 após o lançamento do Plantur em âmbito nacional (ocorrido em 1992). Nessa lei, ficou estabelecido que caberia ao Estado a "preservação do produto turístico", incentivando "a sua exploração, dentro dos princípios da racionalidade e da eficiência, e a favorecer a ampliação da demanda turística" (MINAS GERAIS, 1994, art. 3ํㅜ).

A Lei do Planitur-MG foi revogada dois anos mais tarde, por ocasião da instituição do Plano Mineiro de Turismo, alinhado ao então Plano Mineiro de Desenvolvimento Integrado (PMDI), que tinha como princípios a valorização e preservação do patrimônio histórico e natural, a integração e o desenvolvimento econômico das regiões do estado, a promoção no exterior e o desenvolvimento do turismo interno (MINAS GERAIS, 1996). No entanto, segundo Trindade (2009, p. 27), o "plano nunca foi utilizado para definir diretrizes para qualquer ação já realizada pela Setur". Esse período coincide com a implementação do PNMT em âmbito nacional.

Finalmente, em 1999, é criada a Setur-MG por meio da Lei Estadual no 13.341 (MINAS GERAIS, 1999), sendo a primeira secretaria a tratar exclusivamente do turismo no estado. A existência de um órgão do executivo para tratar especificamente do turismo ocorre antes da criação do equivalente na esfera federal - o Ministério do Turismo (MTur), criado apenas em 2003. A Turminas passou então a ser vinculada à Setur-MG até sua incorporação pela Companhia de Desenvolvimento Econômico de Minas Gerais (Codemig) em 2003 (MINAS GERAIS, 2003b). 
A Setur-MG nasce com a finalidade de "planejar, coordenar, fomentar e fiscalizar o turismo, objetivando a melhoria da qualidade de vida das comunidades, a geração de emprego e renda e a divulgação do potencial turístico do Estado" (MINAS GERAIS, 1999, art. 19).

Nas palavras de Bolson (2006, p. 79):

A criação da Setur deu início a construção de uma política pública de turismo baseada na descentralização e regionalização, com a participação ativa da sociedade para definição das prioridades necessárias, para o desenvolvimento do turismo. Estabeleceu-se uma metodologia de indução ou estímulo para que as comunidades localizadas em determinados espaços geográficos se envolvessem de modo consciente e ativo na formação de Circuitos Turísticos. A integração das comunidades e a gestão integrada dos recursos para promover e desenvolver o turismo foram as bases para o desenvolvimento de uma metodologia inovadora para a indução à formação de Circuitos Turísticos em Minas Gerais.

A partir da criação da Setur-MG, surge a política dos Circuitos Turísticos, cuja formação se iniciou no final dos anos 1990 e início dos anos 2000, conforme detalhado na seção a seguir.

Alguns outros acontecimentos posteriores merecem ser destacados na trajetória da política de turismo de Minas Gerais. 0 primeiro deles se refere à criação do Fórum Estadual de Turismo, em 2003, posteriormente transformado em Conselho Estadual de Turismo, cuja composição foi regulamentada pelo Decreto no 45.072 de março de 2009 e, desde então, mantém-se ativo. A despeito de haver um Conselho formalmente instituído em 1983, foi apenas a partir do FET-MG e em especial do CET-MG que se formou um colegiado com uma atuação mais efetiva, reconhecido pela Setur-MG. (MINAS GERAIS, 2009b)

A criação, em 2006, da Federação dos Circuitos Turísticos, entidade representativa das Associações de Circuitos Turísticos, também merece ser enfatizada, dada seu pioneirismo.

Além disso, destaca-se a inclusão do critério turismo na lei estadual que dispõe sobre distribuição de parcela da arrecadação do ICMS (Imposto sobre Circulação de Mercadorias e Serviços) aos municípios mineiros, um grande passo para $\mathrm{o}$ incentivo à gestão turística nas cidades mineiras.

Por fim, é importante citar a reforma administrativa ocorrida no estado em 2013, que culminou com a união entre as pastas de turismo e esportes, formando a Secretaria de Estado de Turismo e Esportes (Setes-MG), que possuía uma subsecretaria para cada uma das áreas (MINAS GERAIS, 2013). Em 2016, no entanto, as secretarias foram novamente desmembradas, com a Setur-MG voltando a ter uma pasta exclusiva.

\section{OS CIRCUITOS TURÍSTICOS: PROCESSO DE FORMAÇÃo E CERTIFICAÇÃo}

De acordo com Gomes (2006), o estado de Minas Gerais lançou a política para estimular a formação de Circuitos Turísticos no final dos anos 90 e início dos anos 2000, ou seja, antes do lançamento do Programa de Regionalização do Turismo - 
Roteiros do Brasil, instituído em âmbito federal em 2004. Conforme já citado anteriormente, antes desse período, a política nacional de turismo era centrada no PNMT, cuja base estimulou a descentralização e a gestão participativa, aspectos relevantes considerados na formação da política de regionalização (ARAÚJO; CÉSAR, 2012).

Voltando ao estado de Minas Gerais, Bolson e Álvares (2005) destacam que a decisão de regionalizar e descentralizar a gestão do turismo no estado se deu por dois motivos principais: (1) a grande extensão territorial do estado e (2) o grande número de municípios: Minas Gerais possui 853 municípios. Além disso, a regionalização permitiria uma diversificação da atividade turística no estado (muito focada nas cidades históricas), estimulando o surgimento de novos destinos integrados e aumentando o tempo médio de permanência do turista.

Com intuito de estimular a discussão acerca da regionalização como instrumento de desenvolvimento turístico, a Setur-MG (gestão 1999-2003) organizou oficinas participativas nas diversas macrorregiões do estado, envolvendo a participação de atores do poder público, iniciativa privada e comunidade local, conforme destacado por Emmerndoerfer (2008). A autora destaca que o objetivo geral das atividades era a sensibilização para a organização do turismo, e as oficinas contaram com a participação direta do então Secretário de Estado de Turismo, Manoel Costa, idealizador do processo, o que garantiu credibilidade à proposta.

Emmerndoerfer (2008) ressalta que foram realizadas 54 oficinas com duração de dois dias, atingido cerca de 400 municípios, alcançando de maneira direta mais de três mil pessoas. Segundo Trindade (2009), esse processo estimulou, até o final de 2003, a formação de 47 circuitos, abrangendo aproximadamente 450 municípios.

0 reconhecimento dessa política se deu em 2003 por meio do Decreto Estadual 43.321, que estabeleceu que os Circuitos Turísticos são:

o conjunto de municípios de uma mesma região, com afinidades culturais, sociais e econômicas que se unem para organizar e desenvolver a atividade turística regional de forma sustentável, através da integração contínua dos municípios, consolidando uma atividade regional. (MINAS GERAIS, 2003a, art. 1oㅗ § 1ํㅜ)

0 decreto estabelece ainda que a Setur-MG é responsável por definir, por meio de resolução, os critérios necessários para o reconhecimento e por expedir o Certificado de Reconhecimento aos Circuitos Turísticos. Portanto, é considerando um Circuito Turístico aquele que cumpre os critérios definidos e recebe tal certificado.

De acordo com Gomes (2006) a Setur-MG recomendava que, para formação de um Circuito, além das afinidades culturais, sociais e econômicas dispostas no decreto, os municípios estivessem localizados em um raio de $100 \mathrm{~km}$ e adotassem uma nomenclatura adequada a sua identidade regional.

A resolução em vigor (MINAS GERAIS, 2014) dispõe que, para requerer o Certificado de Reconhecimento, o circuito deve cumprir minimamente três requisitos básicos: (1) possuir, no mínimo, um ano de existência formal; (2) ser constituído por, no mínimo, cinco municípios de uma mesma região e (3) ser uma entidade sem fins lucrativos, com a finalidade de promoção e desenvolvimento sustentável. Todos os circuitos têm, portanto, personalidade jurídica, variando entre associações (as mais comuns), organizações da sociedade civil de interesse 
público (Oscip) e agências de desenvolvimento. As prefeituras e demais membros associados pagam uma mensalidade aos Circuitos, sendo que cada entidade determina suas regras, tais como valores e formas de repasse. Em geral, as prefeituras municipais repassam recursos via convênio às associações.

Além dos documentos ligados à comprovação de regularidade jurídica, fiscal e trabalhista, os circuitos devem apresentar à Setur-MG o seu planejamento estratégico devidamente aprovado em ata pelos membros, além de um plano de ação anual e o inventário da oferta turística de todos os municípios que o integram. É necessário também indicar uma pessoa para a gestão do circuito, sendo exigido que a entidade tenha em seu quadro ao menos um profissional graduado ou especialista em turismo para desempenhar a função de gestor ou técnico. São ainda exigências: envio de uma carta de intenção dos municípios justificando a sua associação ao Circuito Turístico, inclusão dos dados dos municípios no Portal Oficial de Turismo de Minas Gerais (www.minasgerais.com.br), envio da listagem das empresas, instituições e profissionais que irão compor a entidade, encaminhamento da logomarca correspondente à identidade visual do circuito, envio do calendário oficial de eventos de todos os municípios e da relação dos meios de atendimento e informação ao turistas, tais como centros de atendimento, e-mails, sites, telefones, etc. (MINAS GERAIS, 2014)

Vale destacar que o processo de definição dos municípios que integrarão cada circuito, assim como a nomenclatura a ser adotada, é feito pelos próprios membros, sem intervenção direta da Setur-MG.

A renovação da certificação é requerida anualmente, com diferentes documentos comprobatórios para anos pares e ímpares que devem ser encaminhados à Setur-MG. (MINAS GERAIS, 2014)

De acordo com a Setur-MG (MINAS GERAIS, 2016a), o estado de Minas Gerais conta atualmente com 46 circuitos turísticos:

Figura 1 - Mapa de regionalização do turismo do Estado de Minas Gerais

(Circuitos Turísticos)

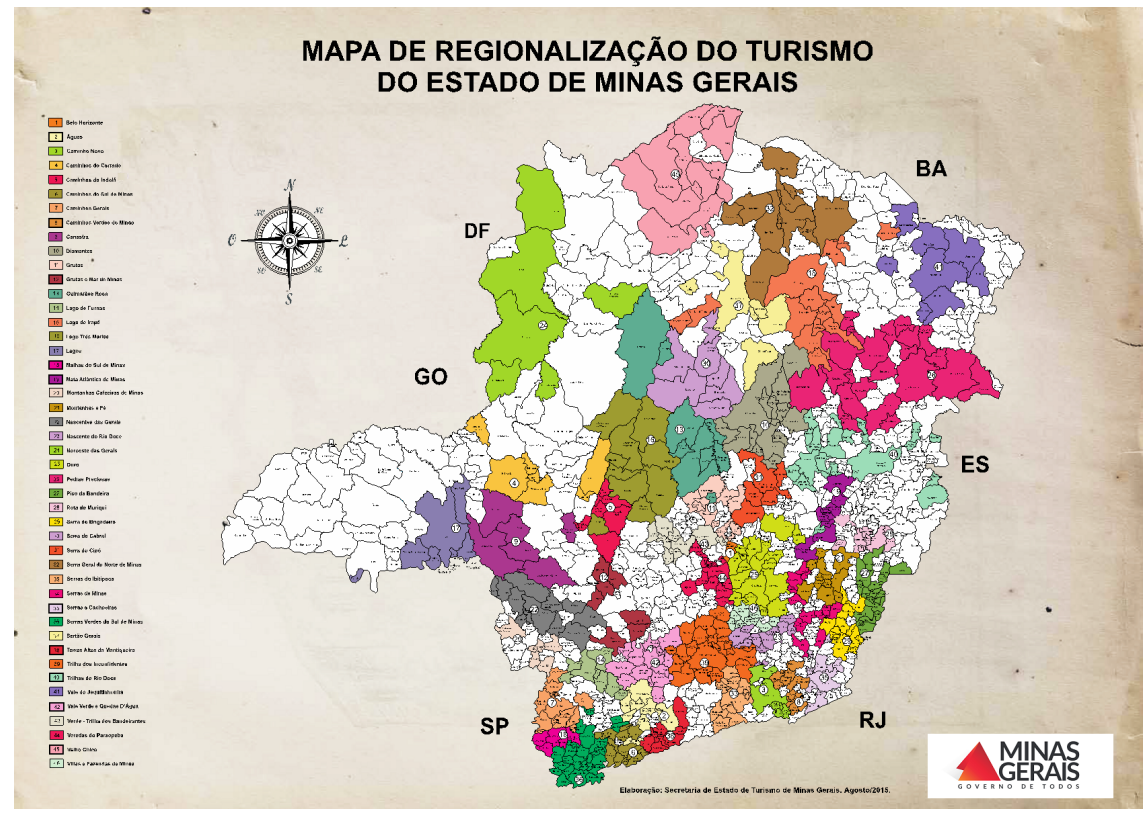

Fonte - Minas Gerais (2016b) 
No ano de 2006, foi fundada a Federação dos Circuitos Turísticos, que congrega as Associações de Circuitos Turísticos, uma importante iniciativa no que diz respeito à ampliação da participação dos circuitos no direcionamento das políticas públicas estaduais. A Fecitur possui personalidade jurídica e é uma entidade de direito privado, sem fins lucrativos. A Federação representa os circuitos turísticos no Conselho Estadual de Turismo (CET-MG), e a participação na Federação é facultativa. Sendo assim, a Fecitur não congrega a totalidade das associações de Circuitos Turísticos (FECITUR, 2016).

Lima (2011) ressalta que, desde a criação dos Circuitos Turísticos, a Setur-MG promoveu uma série de ações com o objetivo de estruturar e profissionalizar as entidades, tais como ações de sensibilização, mobilização, promoção e roteirização, capacitações diversas, além dos repasses voluntários de recursos (convênios) diretamente às associações para estruturação física da sede, aquisição de equipamentos, criação de sites etc.

Percebe-se que o processo de criação dos Circuitos Turísticos em Minas Gerais conta com experiências que podem ser consideradas positivas, tais como o fomento a sua estruturação a partir de um método participativo, o estímulo ao desenvolvimento endógeno do turismo (evidenciado pela a adesão voluntária ao processo), a liberdade para organização ou aglutinação dos municípios em regiões turísticas e o reconhecimento dos circuitos por um decreto estadual. Destaca-se ainda a existência de critérios para sua certificação e reconhecimento, o que envolve a exigência de um mínimo de formalização institucional e de planejamento turístico.

Em 2009, foi conquistado um importante avanço relacionado à política pública do turismo de Minas Gerais e ao Programa de Regionalização: o chamado ICMS Turístico, já citado anteriormente. Trata-se da inclusão do critério turismo na Lei Estadual no 18.030/2009 (MINAS GERAIS, 2009a), que dispõe sobre a distribuição aos municípios mineiros de parcela da arrecadação do Imposto sobre Circulação de Mercadorias e Serviços. Para se habilitar a participar do critério turismo da referida lei, o município deve, minimamente: (1) participar do Programa de Regionalização do Turismo de Minas Gerais, ou seja, deve integrar formalmente um circuito turístico; (2) elaborar uma política municipal de turismo; e (3) constituir e manter em regular funcionamento o Conselho e o Fundo Municipal de Turismo. (MINAS GERAIS, 2009a)

0 percentual do ICMS turístico a ser repassado é definido com base no índice de investimento em turismo do município e o somatório dos índices de investimento em turismo de todos os municípios habilitados a receber o incentivo. 0 cálculo é feito a partir de fórmula matemática estabelecida pela Lei $\mathrm{n}^{\mathrm{o}}$ 18.030/2009. Dessa maneira, o número de municípios habilitados influencia diretamente no valor que cada um recebe individualmente (quanto mais municípios se habilitam, mais diluído se torna o valor a ser repassado). Para a Setur-MG (MINAS GERAIS, 2014, p. 46):

Após a implementação do planejamento e das ferramentas de gestão municipal para o turismo, o município estará apto a pleitear o ICMS Turístico. A inclusão do critério 'turismo' na distribuição de parcela de arrecadação do ICMS Estadual foi uma importante conquista dos municípios mineiros, uma vez que prima pela organização municipal turística e o desenvolvimento do turismo local. Pela primeira 
vez na história da economia brasileira, municípios passaram a receber recursos do ICMS para trabalharem a sua gestão turística.

Vale destacar que, na ocasião da inclusão do critério do turismo na referida lei, a Fecitur teve um papel importante de articulação junto à Setur-MG e à Assembleia Legislativa de Minas Gerais. (FECITUR, 2016)

\section{ACORRELAÇÃo ENTRE OS CIRCUITOS TURÍSTICOS E A GOVERNANÇA}

De acordo com Barbosa (2012), o processo de descentralização é um fator fundamental para o desenvolvimento do turismo baseado no protagonismo local e no poder compartilhado. Isso, conforme destacado pela autora, pode se dar no contexto municipal, regional ou estadual, por meio de conselhos, fóruns, comitês, associações.

A descentralização aqui abordada tem relação direta com conceitos ligados a participação social e governança. Camargo (2003, p. 307) destaca que a governança tem a ver com "atividades apoiadas em objetivos comuns e partilhados", abrangendo desde instituições governamentais até aquelas de caráter não governamental. Ele destaca, no entanto, que a governança funciona quando é aceita "pelos principais atores de um determinado processo".

Barbosa (2012) ressalta ainda que o conceito de governança é mais amplo que o conceito de governo, que é representado por uma autoridade formal, com autoridades políticas e atribuições ligadas à condução e implementação de políticas públicas.

É importante ressaltar, no entanto, que governança pode ser um aspecto instrumental da governabilidade, conforme ponderado por Araújo e César (2012). Já Arturi (2003, p. 80), expõe que a governança é entendida como:

um conjunto de processos, instituições e práticas, através das quais os cidadãos e os diferentes grupos sociais - locais, nacionais e internacionais - articulam seus interesses e posições, formando um complexo sistema de elaboração de políticas e de tomada de decisões mais vasto que a arena estatal.

Para Tomazzoni (2015, p. 1), a governança no turismo tem uma relação íntima com a gestão participativa para o desenvolvimento do setor e deve se fundamentar no planejamento.

No entanto, vale destacar que, apesar de complementares, governança e gestão participativa são conceitos diferentes:

A governança refere-se ao ambiente político e institucional no qual se processam as disputas de interesses e os conflitos e ao processo de coordenação capaz de garantir uma gestão democrática, a participação dos diferentes atores e compartilhar responsabilidades com setor privado e sociedade civil organizada, enquanto que a gestão participativa refere-se mais a processos e instrumentos de tomada de decisões e implementações de ações. São diferentes, no entanto, complementares. (ARNS, 2009, p. 89)

González (2014) destaca que a governança no turismo tem relação com a exigência cidadã de buscar decisões mais coletivas, permitindo aos diferentes atores so- 
ciais maior participação e protagonismo. Nesse sentido, a governança turística seria a busca pela descentralização do processo decisório, principalmente sobre assuntos que envolvem conflitos de interesses que impulsionam processos de inovação social.

Para o Ministério do Turismo, a governança tem ligação com a capacidade de governar, porém pressupõe uma "administração participativa que envolve as populações locais na elaboração, monitoramento e, em alguns casos, na execução de políticas públicas" (BRASIL, 2007, p. 16). As entidades (formais ou não) que atuam no âmbito da governança compartilhada no turismo são chamadas de instâncias de governança pelo MTur.

Com a criação do Programa de Regionalização do Turismo - Roteiros do Brasil, em 2004, foi estimulada a criação de tais instâncias de governança regionais no turismo, como parte da estratégia de descentralização, cooperação e empoderamento social, incentivando o protagonismo das regiões. Nas palavras do MTur (BRASIL, 2007, p. 16):

Ao considerar as diretrizes e princípios de integração, gestão coordenada, participação e descentralização do Programa [de Regionalização], as Instâncias de Governança Regionais passam a ser responsáveis pela definição de prioridades, pela coordenação das decisões a serem tomadas, pelo planejamento e execução do processo de desenvolvimento do turismo na região turística. Devem participar, também, nas decisões politicas, econômicas e sociais no âmbito regional.

A partir dos conceitos apresentados, pode-se considerar os Circuitos Turísticos de Minas Gerais como instâncias de governança regionais.

Pelo menos em tese (já que nem sempre isso ocorre em todos os casos), os circuitos turísticos congregam os principais atores ligados ao turismo nas regiões (poder público, empresariado, sociedade civil) e são responsáveis pela discussão, pela união de diferentes interesses e pela tomada de decisão acerca do planejamento de ações para o desenvolvimento turístico em âmbito regional.

Para o MTur (BRASIL, 2007), as instâncias de governança têm como objetivos a criação de uma comunicação regional, a mobilização dos atores ligados ao turismo, a coordenação do processo de regionalização, o apoio à descentralização, o planejamento, a monitoria e avaliação de ações ligadas ao desenvolvimento turístico, entre outros.

Apesar do pioneirismo de Minas Gerais e dos aspectos positivos relacionados à política pública e à governança, alguns estudos apontam ainda para algumas dificuldades e fragilidades nesse processo de regionalização do turismo.

Um desses estudos, uma pesquisa conduzida por Lima (2011) e realizada por pesquisadores da Universidade Federal de Viçosa (UFV), teve como objetivo avaliar a implementação da política de Circuitos Turísticos de Minas Gerais a partir de análises secundárias e entrevistas com dirigentes de 37 circuitos turísticos, além de gestores da Setur-MG. Tal pesquisa aponta, como aspectos positivos da política, uma maior organização da atividade turística no estado, a descentralização, a criação da Fecitur, o recebimento de prêmios pelo Ministério do Turismo no âmbito do Programa de Regionalização - Roteiros do Brasil, a integração dos municípios para o desenvolvimento da região, o despertar para o turismo de municípios que antes não enxergavam a atividade como estratégica e a possibilidade de discutir a política de turismo junto ao governo estadual (LIMA, 2011). 
Entre as fragilidades apontadas, estão a alta dependência dos circuitos turísticos com relação à Setur-MG, a dificuldade de sustentabilidade financeira dos circuitos tendo em vista a alta inadimplência dos associados e a limitação na arrecadação de recursos; a dificuldade de posicionar o turismo como prioridade frente aos prefeitos municipais, a descontinuidade de políticas das prefeituras em mudanças de gestão, bem como a ausência de mecanismos formais ou ferramentas para avaliação dos resultados da política estadual de regionalização do turismo pela Setur-MG (LIMA, 2011).

Além das questões já elencadas, Sette, Valle e Coutinho (2014) enfatizam que, apesar de grande parte dos gestores dos circuitos turísticos reconhecerem a política de regionalização do estado como uma iniciativa importante e terem consciência do seu papel enquanto instâncias de governança regionais do turismo, algumas observações merecem ser feitas, tais como: os gestores têm dificuldade no desenvolvimento de ações que alcancem resultados em curto prazo, o que torna frágil a percepção dos benefícios da atividade turística e da atuação dos circuitos por parte das prefeituras municipais; há necessidade de criação de uma lei estadual que disponha sobre os circuitos turísticos, hoje reconhecidos apenas por decreto; a Setur-MG tem um papel fundamental como indutora do processo de regionalização e, muitas vezes, sucessivas mudanças de gestão e da equipe técnica resultaram em descontinuidades; e, por fim, há certa falta de clareza no que diz respeito as diretrizes da política em âmbito estadual.

\section{RESULTADOS: DIFICULDADES E PERSPECTIVAS PARA O AVANÇO DA POLÍtTCA DE REGIONALIZAÇÃo DE MINAS GERAIS}

Primeiramente, os entrevistados para esta pesquisa foram questionados sobre as dificuldades e fragilidades da Política de Regionalização de Minas Gerais, considerando primordialmente os aspectos levantados por Lima (2011) citados anteriormente, tais como a dependência dos circuitos turísticos em relação à Setur-MG, o problema da sustentabilidade financeira, a dificuldade de posicionar o turismo como prioridade e a descontinuidade política das prefeituras. Nas entrevistas, foi possível perceber que tais dificuldades ainda não foram superadas. A questão orçamentária e a alta inadimplência, agora somadas à crise financeira e política pela qual o Brasil vem passando (o que deixa os municípios em situação ainda mais fragilizada) são uma realidade. 0 turismo ainda não é visto como prioridade por grande parte dos gestores públicos municipais, embora o ICMS Turístico, segundo entrevistados, tenha contribuído para uma mínima organização em âmbito municipal e para o aumento, ainda que tímido, do interesse dos prefeitos no turismo.

Quando questionados se os entrevistados acreditavam que, em um horizonte de dez anos, haveria mudança com relação às dificuldades enfrentadas pelos circuitos turísticos, a maior recorrência de respostas foi "em parte". A mudança, de acordo com alguns entrevistados, poderia ocorrer caso houvesse mais apoio e atenção de órgãos públicos e da iniciativa privada. Gestores da Setur-MG acreditam que há perspectiva de melhoria na medida em que a política se consolida, porém as "mudanças são gradativas e lentas" (ENTREVISTADO 7). Um dos entrevistados da Setur-MG apontou que é fundamental criar mecanismos e condições 
para um melhor gerenciamento dos circuitos turísticos e, só assim, as dificuldades seriam superadas.

Aqueles que responderam que "sim", haverá mudanças, alegaram que os progressos se darão em função de uma perspectiva de melhoria na distribuição do ICMS Turístico, com possibilidade de aumento da alíquota destinada ao setor. Além disso, tais entrevistados dizem perceber um "esforço maior das associações em criar projetos sem a participação da Setur, diminuindo a dependência" (ENTREVISTADO 1).

Foi ainda destacado que:

Essas dificuldades e entraves já foram identificados pelos órgãos estaduais que implementam as políticas públicas no estado de Minas. Nos encontros e reuniões realizados com os presidentes e gestores dos circuitos, essa temática tem sido debatida na busca de soluções para os problemas. Acredito que em um horizonte de dez anos ocorram melhoras nesse cenário. (ENTREVISTADO 9 - Gestor de circuito turístico)

A necessidade de melhoria no ICMS Turístico foi apontada por diversos entrevistados: alguns afirmam que os critérios exigidos são frágeis e insuficientes para privilegiar aqueles que realmente investem no turismo como estratégia de desenvolvimento. Vários respondentes afirmam que alguns municípios apresentam documentações sem legitimidade com o intuito restrito de se habilitarem a receber os valores. Isso faz com que um número cada vez maior de municípios se credencie e, conforme já destacado, quanto mais municípios se habilitam, menos cada um recebe individualmente.

Além disso, foi citado que o amadurecimento da atuação e do posicionamento dos Conselhos Municipais de Turismo pode contribuir para melhorias futuras no Programa de Regionalização, uma vez que governanças municipais consolidadas tendem a contribuir para o fortalecimento da gestão regional. A criação da Lei Estadual de Turismo e, consequentemente, a regulação dos circuitos por lei também foi citada como frutífera.

Essa lei irá tratar de assuntos e decisões que são de extrema importância para a gestão e sobrevivência da atividade turística e dos circuitos. Uma delas é a questão de respeitar os fundamentos da regionalização e fazer com que os municípios respeitem esse quesito fundamental para o desenvolvimento turístico regional. Sai prefeito e entra prefeito e eles mudam de circuito como se "esse circuito não me agrada e mudo para outro", ou "o meu amigo que é prefeito é presidente daquele outro circuito e vou me associar com aquele circuito por questões de amizade ou particulares". São questões fundamentais e de entendimento de um gestor sério comprometido com o desenvolvimento de seu município e região. (ENTREVISTADO 6 - Gestor de circuito turístico)

Aqueles que responderam que não há perspectivas de mudança possuem uma visão mais pessimista sobre o futuro do Programa de Regionalização. Um deles (ENTREVISTADO 3 - Gestor de circuito turístico) afirmou que grande parte dos circuitos possui uma arrecadação financeira extremamente baixa e que o estado "brinca" de regionalização do turismo. Tal entrevistado afirmou que, no próximo ano, vários circuitos podem encerrar suas atividades em função da dificuldade financeira. 


\section{Outro entrevistado afirma:}

Não vejo movimentações e nem mudanças de comportamento no estado, nos municípios e principalmente nos empresários da cadeia produtiva do turismo. Sinceramente, e infelizmente, tenho a sensação que a regionalização é boa para aqueles que estão em posição de desfavorecimento em relação à região em que eles se enquadram ou em relação ao tamanho da atratividade turística de sua localidade. Caso contrário, vejo poucos esforços em direção ao crescimento e melhor desempenho da regionalização do turismo. (ENTREVISTADO 5 - Gestor de circuito turístico)

Os entrevistados também foram questionados sobre o impacto da crise econômica e política pela qual o Brasil está passando (o que gera certa instabilidade com relação às perspectivas para a política nacional de turismo) no avanço do Programa de Regionalização de Minas Gerais. Grande parte dos entrevistados acreditam que a crise vem agravando as dificuldades: as instabilidades se refletem inevitavelmente em âmbito estadual e municipal e, consequentemente, na política de regionalização. 0 entrevistado 6 destacou ainda que a falta de credibilidade dos órgãos públicos e de seus gestores diante do cenário atual contribui com uma certa descrença e desunião das populações locais, tornando a mobilização e articulação mais difíceis.

Outros acreditam que a crise não impacta diretamente o programa mineiro, uma vez que se trata de uma política anterior à própria diretriz nacional e possui independência:

A política de regionalização do turismo em Minas Gerais sempre foi independente da política federal. 0 cenário do programa federal sempre foi muito instável, visto que grande parte dos projetos da entidade não possui continuidade. Assim, acredito que irá se manter mesmo sem força em âmbito federal. (ENTREVISTADO 1 - Setur-MG)

O programa de Regionalização em Minas acompanha a Política Nacional, por outro lado, o Estado de Minas Gerais iniciou seu processo de regionalização através da criação dos Circuitos Turísticos mesmo antes do MTur implementar o programa. Penso que mesmo que haja mudanças no cenário nacional, Minas Gerais, de acordo com os rumos da política de turismo do estado, tenderá a manter a regionalização pensando sempre na integração do território. (ENTREVISTADO 9 - Gestor de Circuito Turístico)

Em seguida, questionou-se se é considerada importante a regulamentação dos Circuitos Turísticos por lei, uma vez que o programa é reconhecido apenas por decreto. A maioria dos entrevistados considera que esse seria um avanço importante e necessário ao Programa de Regionalização. Os entrevistados da Setur-MG afirmaram que a minuta da Lei Estadual de Turismo (que tratará também do Programa de Regionalização) já foi elaborada e se encontra sob análise da Secretaria de Estado da Casa Civil e Relações Institucionais (Seccri-MG) e posteriormente seguirá para a ALMG. Apesar de alguns acreditarem que o registro dos Circuitos em lei é apenas uma formalidade, todos foram unânimes em destacar a relevância da medida, pois, segundo um entrevistado da Setur-MG, a lei dá "DNA, dá pedigree" (ENTREVISTADO 10 Setur-MG). Entretanto, um entrevistado destacou que a criação da lei ajuda, 
porém não garante a sustentação do programa, sendo necessários maiores investimentos na profissionalização dos Circuitos.

A última questão abordada tratou do futuro do Programa de Regionalização de uma maneira mais ampla. Nessa questão, percebeu-se que a visão dos gestores da Setur-MG é de certa forma otimista, tendo sido destacado que a base da política está consolidada e que o programa seguirá avançando:

Creio que a base da política está consolidada, não abrindo muita margem para mudanças estruturais no futuro, como, por exemplo, a troca de municípios e a baixa participação da iniciativa privada. Mas acredito no fortalecimento do programa e consolidação e diversificação de mais destinos turísticos no estado. (ENTREVISTADO 1 - Setur-MG)

Acredito que o programa será aprimorado, contribuindo melhor para direcionar a atuação e investimentos dos órgãos públicos e empresas nas regiões turísticas. Através do agrupamento dos municípios e regiões em diferentes categorias, processo iniciado recentemente em nível federal e estadual, poderão ser melhores direcionados os projetos, de acordo com as necessidades e possibilidades de cada região, otimizando-se assim a aplicação dos recursos investidos no setor. (ENTREVISTADO 7 - Setur-MG)

Um dos entrevistados destacou que, no futuro, pode ocorrer uma "seleção natural" no número de circuitos e municípios integrantes do Programa de Regionalização, porém isso não seria negativo:

Acredito que haverá uma seleção em que apenas as instituições mais organizadas e com fluxo turístico e direcionamentos turísticos claros irão permanecer, havendo, portanto, um enxugamento na quantidade de circuitos e municípios que compõem o mapa estadual de regionalização. (ENTREVISTADO 8 - Setur-MG)

Entre os gestores de circuitos, alguns apontaram um futuro promissor, tendo como desafio central a profissionalização e sustentabilidade financeira, além do fortalecimento das instâncias. Mais uma vez, a regulamentação da lei dos Circuitos Turísticos, o aumento da alíquota e mudanças nos critérios de habilitação do ICMS Turístico foram citados como necessários ao avanço do programa.

Apenas dois entrevistados, ambos gestores de circuitos turísticos, citaram perspectivas mais negativas, prevendo que, caso o programa não seja melhor atendido pelo estado, pode caminhar para seu fim:

Não vejo muito futuro pela frente e quem vê é porque ainda não sabe da atual realidade dos circuitos hoje. (ENTREVISTADO 3 - Gestor de Circuito Turístico)

Se ele [o programa] for bem fomentado, bem cuidado pelo estado, Setur-MG e prefeituras, o programa estará mais consolidado, caso contrário, tememos o fechamento. (ENTREVISTADO 4 - Gestor de Circuito Turístico)

A seguir, apresenta-se um quadro-síntese com os principais resultados aferidos na pesquisa: 
Quadro 1 - Síntese dos principais resultados da pesquisa

\begin{tabular}{|c|c|c|}
\hline Item & Aspectos levantados & Detalhamento \\
\hline \multirow{3}{*}{$\begin{array}{l}\text { Dificuldades e } \\
\text { fragilidades da política } \\
\text { de regionalização do } \\
\text { turismo de MG }\end{array}$} & Dependência & $\begin{array}{l}\text { Alta dependência dos Circuitos Turísticos da } \\
\text { Setur-MG. }\end{array}$ \\
\hline & $\begin{array}{l}\text { Sustentabilidade } \\
\text { financeira }\end{array}$ & $\begin{array}{l}\text { Dificuldade de sustentabilidade financeira } \\
\text { dos circuitos turísticos associada à } \\
\text { inadimplência e dificuldade de mobilização e } \\
\text { comprometimento dos municípios. }\end{array}$ \\
\hline & $\begin{array}{l}\text { Descontinuidade } \\
\text { política }\end{array}$ & $\begin{array}{l}\text { Mudanças de gestão nas prefeituras } \\
\text { implicam em descontinuidade da política de } \\
\text { turismo, que não é vista como prioridade. }\end{array}$ \\
\hline $\begin{array}{l}\text { Impacto da crise } \\
\text { econômica e política } \\
\text { do Brasil na política de } \\
\text { regionalização de MG }\end{array}$ & $\begin{array}{l}\text { Reflexos da crise em } \\
\text { âmbito regional e } \\
\text { local }\end{array}$ & $\begin{array}{l}\text { Instabilidades se refletem em âmbito } \\
\text { estadual e municipal e, consequentemente, } \\
\text { na política de regionalização. }\end{array}$ \\
\hline $\begin{array}{l}\text { Criação de uma } \\
\text { Lei Estadual para } \\
\text { regulamentação dos } \\
\text { Circuitos Turísticos }\end{array}$ & Regulamentação & $\begin{array}{l}\text { Criação da Lei Geral do Turismo do estado: } \\
\text { avanço importante e necessário ao Programa } \\
\text { de Regionalização. }\end{array}$ \\
\hline \multirow{5}{*}{ Desafios } & \multirow{2}{*}{$\begin{array}{l}\text { Gestão dos Circuitos } \\
\text { Turísticos }\end{array}$} & $\begin{array}{l}\text { Profissionalização e sustentabilidade } \\
\text { financeira dos circuitos. }\end{array}$ \\
\hline & & $\begin{array}{l}\text { Criar mecanismos e condições para um } \\
\text { melhor gerenciamento dos circuitos } \\
\text { turísticos. }\end{array}$ \\
\hline & ICMS Turístico & $\begin{array}{l}\text { Aumento da alíquota do ICMS Turístico, bem } \\
\text { como revisão dos critérios de habilitação } \\
\text { dos municípios. }\end{array}$ \\
\hline & \multirow{2}{*}{$\begin{array}{l}\text { Política de } \\
\text { Regionalização }\end{array}$} & $\begin{array}{l}\text { Fortalecimento e aprimoramento da Política } \\
\text { de Regionalização. }\end{array}$ \\
\hline & & $\begin{array}{l}\text { Necessário mais apoio e atenção de órgãos } \\
\text { públicos e da iniciativa privada. }\end{array}$ \\
\hline \multirow{5}{*}{ Perspectivas } & \multirow[b]{3}{*}{ Positivas } & $\begin{array}{l}\text { A base da política está consolidada e } \\
\text { necessita ser fortalecida e aprimorada. }\end{array}$ \\
\hline & & $\begin{array}{l}\text { "Seleção natural” no número de circuitos } \\
\text { e municípios integrantes do Programa de } \\
\text { Regionalização, o que é positivo. }\end{array}$ \\
\hline & & $\begin{array}{l}\text { O amadurecimento da atuação dos } \\
\text { Conselhos Municipais de Turismo } \\
\text { contribuirá positivamente, uma vez que } \\
\text { governanças municipais consolidadas } \\
\text { colaboram com o fortalecimento da gestão } \\
\text { regional. }\end{array}$ \\
\hline & \multirow{2}{*}{ Negativas } & $\begin{array}{l}\text { Alguns circuitos podem encerrar suas } \\
\text { atividades em função da dificuldade } \\
\text { financeira. }\end{array}$ \\
\hline & & $\begin{array}{l}\text { Possível fim do Programa de Regionalização, } \\
\text { caso não seja melhor atendido pelo Governo } \\
\text { do Estado. }\end{array}$ \\
\hline
\end{tabular}

Fonte - Elaborado pela autora 
A partir dos resultados apresentados, percebe-se que o Programa de Regionalização do Turismo de Minas Gerais possui inúmeros desafios para sua efetiva consolidação.

\section{CONCLUSÃo}

O Programa de Regionalização do Turismo de Minas Gerais é constantemente citado como referência em discussões acerca de modelos de desenvolvimento turístico, principalmente em função de sua característica bottom up ${ }^{1}$, ou seja, voltada ao desenvolvimento endógeno e fortalecimento e protagonismo das regiões, com pouca intervenção direta dos órgãos estaduais na constituição das instâncias de governança regionais, os circuitos turísticos.

0 pioneirismo de Minas Gerais no que diz respeito a regionalização é inquestionável. Apesar disso, a pesquisa apontou que o programa ainda possui muitas fragilidades que dificultam a sua efetiva consolidação.

Estudos anteriores apontaram dificuldades vivenciadas pelos circuitos turísticos que ainda estão longe de ser superadas. A principal e mais citada foi a questão da sustentabilidade financeira das associações, agravada pela alta inadimplência dos municípios associados, que se encontram em situação ainda mais fragilizada em função da crise no governo federal. Grande parte dos municípios são altamente dependentes do repasse de recursos federais, e o cenário econômico e político atual influencia diretamente na capacidade de investimento das prefeituras. Soma-se a isso a queda na arrecadação tributária do estado de Minas Gerais, fruto da instabilidade econômica. A carência de recursos para investimentos em áreas geralmente prioritárias como saúde, educação e segurança torna ainda mais escassos os recursos financeiros e técnicos disponíveis para investimento no turismo em âmbito municipal.

A dificuldade financeira dos circuitos turísticos se configura em uma fragilidade alarmante, que pode inclusive colaborar com o encerramento das atividades das entidades mais afetadas, conforme citado por alguns gestores. Apesar dos avanços com o chamado ICMS Turístico, o turismo ainda não é visto como prioridade por grande parte dos prefeitos, e a descontinuidade política é constante.

Como perspectiva para os próximos anos, foi percebido que há grande expectativa em relação à criação da Lei Geral do Turismo de Minas Gerais, cuja minuta está sob análise da Seccri-MG. Tal lei irá reconhecer a existência dos Circuitos Turísticos (que atualmente é feita apenas por Decreto) e do Programa de Regionalização de Minas Gerais. Apesar da lei não garantir, por si só, a sustentação do programa, trata-se de um aspecto relevante que pode contribuir para a sua maior credibilidade junto aos atores regionais e ao próprio Governo do Estado.

A necessidade de revisão dos critérios de habilitação no ICMS Turístico e o aumento da alíquota destinado ao turismo também foram apontados como necessários, de modo a tornar o incentivo mais robusto e direcionado aos municípios que de fato investem e apostam no turismo como estratégia de desenvolvimento.

1. Expressão em inglês que significa "de baixo para cima” (tradução do autor). 
Alguns entrevistados acreditam que, nos próximos dez anos, o Programa de Regionalização de Minas Gerais avançará e será aprimorado. A evolução pode, inclusive, significar uma diminuição do número de circuitos e municípios participantes, o que não necessariamente deve ser entendido como negativo. A redução pode contribuir para uma atuação mais focada naquelas regiões onde o turismo é efetivamente um fator de desenvolvimento econômico e promotor da melhoria do bem-estar social.

Por fim, considera-se importante ponderar que o turismo é um fenômeno complexo e o seu desenvolvimento depende de diversos fatores, muitos deles externos aos destinos, ao estado e até ao próprio país. Não há fórmulas padronizadas que gerem sucessos garantidos ou derrotas. Há, na verdade, um conjunto de práticas e processos que se adequam mais ou menos a realidade de cada destino. Nesse sentido, estabelecer estratégias de desenvolvimento turístico únicas em um estado tão grande e diverso como Minas Gerais é, sem dúvidas, um desafio enorme. A regionalização do turismo tem se mostrado uma política interessante, que gerou importantes e reconhecidas conquistas. Porém, percebe-se que há fragilidades e dificuldades que se mantêm ou se agravam com o passar dos anos. Promover a melhoria da capacidade de gerenciamento e profissionalização dos circuitos turísticos, assim como um fortalecimento das instituições perante os territórios é imprescindível para o avanço do programa. É fundamental que a Setur-MG, enquanto órgão gestor e indutor do programa, promova medidas em parceria com os circuitos turísticos e a Fecitur visando a melhoria da capacidade de gerenciamento dos circuitos, assim como um fortalecimento das entidades em seus territórios rumo ao efetivo empoderamento e protagonismo das regiões.

\section{REFERÊNCIAS}

ARAÚJO, C. M.; CÉSAR, P. de A. B. Dimensão político-institucional do turismo no Brasil. In: BENI, M. C. (Org.) . Turismo: planejamento estratégico e capacidade de gestão: desenvolvimento regional, rede de produção e clusters. Barueri: Manole, 2012. p. 257-281.

ARAÚJO, C. M.; TASCHNER, G. Turismo e Políticas Públicas no Brasil. In: BENI, M. C. (org). Turismo: planejamento estratégico e capacidade de gestão: desenvolvimento regional, rede de produção e clusters. Barueri: Manole, 2012. p. 69-86.

ARNS, P. C. Governança democrática e desenvolvimento territorial: avanços e limites das iniciativas brasileiras. In: ZAPATA, T. (Org.). Desenvolvimento local e a nova governança. Recife: IADH, 2009. p. 79-111.

ARTURI, C. S. Os desafios para a instauração de uma governança mundial democrática na atual conjuntura internacional: síntese de um debate. Revista Indicadores Econômicos FEE, Porto Alegre, v. 31, n. 1, p. 75-94, 2003.

BARBOSA, A. L. Relações organizacionais para o desenvolvimento regional do turismo. In: BENI, M. C. (Org.). Turismo: planejamento estratégico e capacidade de gestão: desenvolvimento regional, rede de produção e clusters. Barueri: Manole, 2012. p. 131-155.

BOLSON, J. H. G. Turismo e políticas públicas: uma análise da implementação dos Circuitos Turísticos de Minas Gerais através da percepção dos seus gestores, empresários e comunidade local. 2006. Dissertação (Mestrado em Turismo e Meio Ambiente) - Centro Universitário UNA, Belo Horizonte, 2006. 
BOLSON, J. H. G.; ÁLVARES, L. C. Descentralização e democratização da gestão pública: a implantação dos circuitos turísticos em Minas Gerais. 2005. Disponível em: <http://bit. ly/2nwqb2b>. Acesso em: 19 abr. 2016.

BRASIL. Ministério do Turismo. Avaliação do Programa de Regionalização do Turismo: Roteiros do Brasil: Resumo Executivo. Brasília: Ministério do Turismo, 2010. Disponível em: <http://bit.ly/2nJd118>. Acesso em: 10 maio 2016.

. Ministério do Turismo. Programa de Regionalização do Turismo: Roteiros do Brasil: Módulo Operacional 3: Institucionalização da Instância de Governança Regional. Brasília: Ministério do Turismo, 2007. Disponível em: <http://bit.ly/2mDw4tK>. Acesso em: 17 mar. 2017.

CAMARGO, A. A. Governança para o Século 21. In: TRIGUEIRO, M. A. (Ed.). Meio ambiente no século 21: 21 ambientalistas falam da questão ambiental nas suas áreas de conhecimento. Campinas: Autores Associados, 2003.

CORIOLANO, L. N.; SAMPAIO, C. A. C. Discursos e concepções teóricas do desenvolvimento e perspectivas do turismo como indução. In: BRASILEIRO, M. D. S.; MEDINA, L. N.; CORIOLANO, L. N. (Orgs.). Turismo, cultura e desenvolvimento. Campina Grande: EDUEPB, 2012. p. 49-73.

EMMENDOERFER, L. A política pública de regionalização do turismo em Minas Gerais: os circuitos turísticos. Turismo em Análise, São Paulo, v. 19, n. 2, p. 221-240, 2008.

FECITUR. Federação dos Circuitos Turísticos. Três Marias: Fecitur, 2016. Disponível em: <http://www.fecitur.org.br>. Acesso em: 4 maio 2016.

GOMES, B. M. A. Política de regionalização do turismo em Minas Gerais: uma análise sob a ótica dos custos de transação. 2006. Dissertação (Mestrado em Administração) - Universidade Federal de Lavras, Lavras, 2006.

GONZÁLEZ, M. V. Gobernanza turística: Políticas públicas innovadoras o retórica banal? Caderno Virtual de Turismo, Rio de Janeiro, v. 14, n. 1, p. 9-22, 2014.

HALL, C. M. Tourism planning: policies, processes and relationships. Harlow: Prentice Hall, 2000.

LIMA, A. A. T. de F. de C. Avaliação da Implementação da Política de Circuitos Turísticos de Minas Gerais: Relatório de Pesquisa. Viçosa: Universidade Federal de Viçosa, 2011.

MINAS GERAIS. Constituição do Estado de Minas Gerais. 17. ed. Belo Horizonte: Assembleia Legislativa do Estado de Minas Gerais, 2017. Disponível em: <http://bit.ly/2mTIr7t $>$. Acesso em: 17 mar. 2017.

. Decreto Estadual no 23.373, de 24 de janeiro de 1984. Dispõe sobre o Sistema Operacional de Esportes, Lazer e Turismo. Legislação mineira. Belo Horizonte, 25 jan. 1984. Disponível em: <http://bit.ly/2necLdW>. Acesso em: 15 abr. 2016.

. Decreto Estadual no 43.321, de 8 de maio de 2003. Dispõe sobre o reconhecimento dos Circuitos Turísticos e dá outras providências. Legislação mineira. Belo Horizonte, 9 maio 2003a. Disponível em: <http://bit.ly/2ns5yrs>. Acesso em: 15 abr. 2016.

. Lei Estadual no 2.268, de 26 de dezembro de 1960. Autoriza a organização de sociedade de economia mista destinada ao aproveitamento e industrialização dos recursos hidrominerais do estado e desenvolvimento do turismo, e dá outras providências. Legislação mineira. Belo Horizonte, 27 dez. 1960. Disponível em: <http://bit.ly/2mTB4Nk>. Acesso em: 15 abr. 2016.

. Lei Estadual no 7.658, de 27 de dezembro de 1979. Autoriza o Poder Executivo a instituir a Empresa Mineira de Turismo - Turminas e dá outras providências. Legislação mineira. Belo Horizonte, 28 dez. 1979. Disponível em: <http://bit.ly/2mTIFvv>. Acesso em: 15 abr. 2016. 
. Lei Estadual no 11.483 , de 7 de junho de 1994. Dispõe sobre o Plano Integrado para o Desenvolvimento do Turismo em Minas Gerais e dá outras providências. Legislação mineira. Belo Horizonte, 8 jun. 1994. Disponível em: <http://bit.ly/2nsa5dm>. Acesso em: 15 abr. 2016.

. Lei Estadual no 12.398, de 12 de dezembro de 1996. Dispõe sobre o Plano Mineiro de Turismo e dá outras providências. Legislação mineira. Belo Horizonte, 12 dez. 1996. Disponível em: <http://bit.ly/2mwLQWt>. Acesso em: 15 abr. 2016.

. Lei Estadual no 13.341, de 28 de outubro de 1999. Dispõe sobre a organização da Governadoria do Estado e da Secretaria de Estado da Casa Civil e Comunicação Social, cria a Secretaria de Estado do Turismo, extingue a Secretaria de Estado de Assuntos Municipais. Legislação mineira. Belo Horizonte, 29 out. 1999. Disponível em: <http://bit. ly/2mTCc3m>. Acesso em: 15 abr. 2016.

. Lei Estadual no 14.892, de 17 de dezembro de 2003. Altera a denominação e o objeto da Companhia Mineradora de Minas Gerais - Comig - e dá outras providências. Legislação mineira. Belo Horizonte, 18 dez. 2003b. Disponível em: <http://bit.ly/2ns570f>. Acesso em: 19 abr. 2016.

. Lei Estadual no 18.030, de 12 de janeiro de 2009. Dispõe sobre a distribuição da parcela da receita do produto da arrecadação do ICMS pertencente aos Municípios. Legislação mineira. Belo Horizonte, 13 jan. 2009a. Disponível em: <http://bit.ly/2nJI6Sp>. Acesso em: 4 maio. 2016.

. Lei Estadual no 18.032, de 12 de janeiro de 2009. Dispõe sobre o Conselho Estadual de Turismo - CET. Legislação mineira. Belo Horizonte, 13 jan. 2009b. Disponível em: <http://bit.ly/2nweOr0>. Acesso em: 4 maio 2016.

. Lei no 21.077, de 27 de dezembro de 2013. Altera as Leis Delegadas no 179 , de $1^{\text {o }}$ de janeiro de 2011, que dispõe sobre a organização básica e a estrutura da Administração Pública do Poder Executivo do Estado, e no 180, de 20 de janeiro de 2011. Legislação mineira. Belo Horizonte, 28 dez. 2013. Disponível em: <http://bit.ly/2n3y7KF>. Acesso em: 15 abr. 2016.

. Secretaria de Estado de Turismo de Minas Gerais. Circuitos turísticos de Minas Gerais. Belo Horizonte: Secretaria de Estado de Turismo de Minas Gerais, 2016a. Disponível em: <http://bit.ly/2n3DVDJ>. Acesso em: 19 abr. 2016.

. Secretaria de Estado de Turismo de Minas Gerais. Mapa de regionalização do turismo do estado de Minas Gerais. Belo Horizonte: Secretaria de Estado de Turismo de Minas Gerais, 2016b. Disponível em: <http://bit.ly/2nwlBRt>. Acesso em: 16 mar. 2017.

- Secretaria do Estado de Turismo e Esportes. Orientações para o planejamento e gestão municipal do turismo em Minas Gerais. Belo Horizonte: Secretaria do Estado de Turismo e Esportes, 2014. Disponível em: <http://bit.ly/2mx1WiQ>. Acesso em: 5 maio 2016.

PEREIRA, C. A. S. Políticas Públicas no Setor de Turismo. Turismo em Análise, São Paulo, v. 10 , n. 2, p. 8-20, 1999.

SETTE, I. R.; VALLE, M. I. M.; COUTINHO, M. P. C. O programa de regionalização do turismo de Minas Gerais: uma abordagem da política pública estadual de turismo. Turismo em Análise, São Paulo, v. 25, n. 3, p. 608-627, 2014.

TOMAZZONI, E. L. A Gestão participativa na inovação e no desenvolvimento do turismo brasileiro. In: ZANIRATO, S. H. (Org.). Participação política: atores e demandas. São Paulo: Annablume, 2015. p. 155-170.

TRENTIN, F.; FRATUCCI, A. C. Política nacional de turismo no Brasil: da municipalização à regionalização. In: INTERNATIONAL CONFERENCE ON TOURISM \& MANAGEMENT 
STUDIES, 2011, Algarve. Proceedings... Algarve: Tourism \& Management Studies, 2011. p. 839-848.

TRINDADE, R. Circuitos turísticos mineiros: descentralização, autonomia e gestão em relação ao turismo de base local: finais dos anos 90-tempo presente. Dissertação (Mestrado em Turismo) - Universidade de Brasília, Brasília, 2009.

VEAL, A. J. Metodologia de pesquisa em lazer e turismo. São Paulo: Aleph, 2011.

Recebido em: 01/08/2016 Aprovado em: 12/03/2017 